\title{
INDENIZAÇÕES EM OBSTETRÍCIA: ESTUDO DAS DECISÕES DO SUPERIOR TRIBUNAL DE JUSTIÇA DO BRASIL DE 2004 A 2014
}

Indemnities in obstetrics: A study of the decisions of the Court of Justice of Brazil 2004-2014

${ }^{1}$ Universidade de São Paulo. Ribeirão Preto/SP, Brasil.

Correspondência: Altacílio Aparecido Nunes. E-mail: altacilio@fmrp.usp.br

Recebido: 25/11/2016. Revisado: 21/03/2017. Aprovado: 28/03/2017. 


\section{RESUMO}

Este artigo tem por objetivo identificar, nas decisões do Superior Tribunal de Justiça (STJ), as principais causas dos danos decorrentes da prática médica obstétrica no momento do parto. O estudo analisou 21 decisões julgadas pela corte entre 2004 e 2014 relacionadas a indenizações judiciais na obstetrícia. O critério de seleção dos casos utilizou como método a busca de decisões no site do STJ, cujos descritores foram: "parto", "erro médico"; "médico"; "paciente"; "profissional da saúde"; "dano moral"; "dano material"; "SUS"; "responsabilidade civil" e "indenização por erro médico". O Rio de Janeiro foi o estado com maior número de ações indenizatórias $(28,6 \%)$ apreciadas pelo STJ, seguido de São Paulo e Minas Gerais, com $14,3 \%$ cada um. No tocante aos réus que figuraram no polo passivo das demandas, $38,1 \%$ eram médicos e hospitais. Verificou-se que $71 \%$ das supostas falhas médicas que originaram as ações ocorreram durante a realização do parto natural, contra $29 \%$ dos casos de cesariana. A principal causa dos danos relatados foi a demora na realização do parto, seguida dos traumatismos. Apesar de pesquisas demonstrarem que a cesariana oferece maiores riscos para a parturiente e o feto, os resultados obtidos das decisões judiciais analisadas pelo STJ evidenciaram que os danos que resultaram sequelas irreversíveis no nascituro foram recorrentes nos casos relacionados ao parto natural, sugerindo que atenção especial deve ser dada à formação médica obstétrica, bem como à compreensão dos aspectos socioculturais envolvendo a indicação e a escolha pelo tipo de parto.

\section{Palavras-Chave}

Cesariana; Erro Médico; Jurisprudência; Obstetrícia; Parto Natural.

\section{ABSTRACT}

This article intends to identify the main reasons of damage caused by obstetric medical practice during childbirth, on the decisions of the Supreme Court of Justice of Brazil. The study analyzed 21 decisions judged between 2004 and 2014 related to legal compensations concerning obstetrics. The criteria for the selection of cases was to search the Supreme Court's website, for decisions containing descriptors such as: "birth", "medical error"; "doctor"; "patient"; "health professional"; "moral damage"; "property damage"; "SUS"; "Liability" and "compensation for medical error". Rio de Janeiro was the state with the largest number of compensation claims (28.6\%) appreciated by the court, followed by São Paulo and Minas Gerais with 14.3\%. Among the defendants listed on the demands, $38.1 \%$ were doctors and hospitals. It was found that $71 \%$ of the alleged malpractices that led to these actions occurred during vaginal delivery and $29 \%$ of cases correspond to caesarean section. The main cause of damages reported was the delays in performing delivery, followed by trauma. Although research has shown that the cesarean section poses greater risks to the woman and the fetus, the results obtained from the decisions analyzed by the court showed that damages resulting in irreversible sequelae in unborn children were recurrent in natural birth related cases, suggesting that special attention should be given to obstetric medical training as well as to the understanding of the sociocultural aspects that surround medical indication and choice of the type of childbirth method.

\section{Keywords:}

Cesarean Section; Jurisprudence; Medical Error; Natural Childbirth; Obstetrics. 


\section{Introdução}

A Organização Mundial da Saúde (OMS) coloca a maternidade segura como prioridade, ao buscar as melhores evidências científicas disponíveis ${ }^{1}$. Estima-se que 287 mil mortes maternas ocorreram em todo o mundo em $2010^{2}$, sendo que mais de 50 milhões de mulheres sofrem doenças ou sequelas relacionadas com a gravidez e pelo menos 1,2 milhão de recém-nascidos morrem por complicações durante o ciclo gravídico-puerperal ${ }^{3}$.

No Brasil, a morte de mulheres durante a gravidez, parto ou puerpério foi reduzida de forma acentuada ${ }^{1,3}$ : em 1990, ocorriam 141 óbitos/100 mil nascidos vivos; em 2011, a taxa ficou em menos de 64/100 mil' . Entre 2011 e 2012, a Fundação Oswaldo Cruz (Fiocruz) coordenou a pesquisa "Nascer Brasil", com 23.940 mulheres, mostrando que $54 \%$ dos nascimentos eram por cesarianas, ao passo que as recomendações da OMS são para que apenas de $10 \%$ a $15 \%$ sejam por procedimento cirúrgico. A pesquisa aponta que a mortalidade materna segundo os grupos de risco de mortalidade materna direta (como hipertensão, hemorragia, infecção puerperal e aborto) demonstra um declínio considerável entre 1990 a 2011, ao passo que causas ligadas ao risco de mortalidade materna indireta ainda contam com número crescente de mortes ${ }^{5,6}$.

Outra grande preocupação é o aumento da prematuridade no Brasil. A proporção de nascimentos antes de 37 semanas de gestação encontrada nesse estudo foi de $11,3 \%, 50 \%$ a mais do que em países desenvolvidos. Em relação aos recém-nascidos com 37 ou 38 semanas gestacionais, a proporção foi de $35 \%$. A Fiocruz entende que, embora não sejam considerados prematuros, são nascituros que poderiam ganhar mais peso e maturidade se tivessem a chance de chegar a 39 semanas ou mais de gestação ${ }^{5,6}$. Segundo o $5^{\circ}$ Relatório Nacional de Acompanhamento

\footnotetext{
${ }^{1}$ WORLD HEALTH ORGANIZATION - WTO. Care in normal birth: a practical guide. Geneva, Switzerland, 1996. Disponivel em: <http://whqlibdoc.who.int/hq/1996/WHO_FRH_MSM_96.24.pdf>. Acesso em: 09 out. 2015. ${ }^{2}$ ALENCAR JÚNIOR, C. A. Os elevados índices de mortalidade materna no Brasil: razões para sua permanência [Editorial]. Rev Bras Ginecol Obstet., v. 28, n. 7, p. 9-11, 2006. Disponível em: <http://www.scielo.br/pdf/ rbgo/v28n7/01.pdf>. Acesso em: 04 dez. 2015.

${ }^{3}$ MOURA, F. M. J. S. P. et al. Humanization and nursing assistance to normal childbirth. Rev Bras Enferm, Brasília, v. 60, n. 4, p. 452-455, jul./ago. 2007. Disponível em: <http://www.scielo.br/pdf/reben/v60n4/ a18.pdf>. Acesso em: 25 out. 2015.

${ }^{4} \mathrm{CAl}$ a mortalidade materna no mundo, aponta OMS; redução no Brasil chega a 43\%, 2014. ONUBR. Nações Unidas no Brasil, 07 maio 2014. Disponível em: <http://www.onu.org.br/cai-a-mortalidade-materna-nomundo-aponta-oms-reducao-no-brasil-chega-a-43/>. Acesso em: 30 nov. 2015.

${ }^{5}$ NASCER no Brasil. Pesquisa revela número excessivo de cesarianas. Agência Fiocruz de Notícias, 30 maio 2014. Disponível em: <http://portal.fiocruz.br/pt-br/content/pesquisa-revela-numero-excessivo-decesarianas-no-pais>. Acesso em: 25 fev. 2016.

${ }^{6}$ VASCONCELLOS, M. T. L. et al. Desenho da amostra Nascer no Brasil: Pesquisa Nacional sobre Parto e Nascimento. Cad. Saude Publica, v. 30, supl. 1, p. 49-58, 2014. Disponível em: <http://www.scielo.br/pdf/ csp/v30s1/0102-311X-csp-30-s1-0049.pdf>. Acesso em: 14 mai. 2015. http://dx.doi.org/10.1590/0102$311 \times 00176013$.
} 
das Metas, a elevada percentagem de cesarianas representa um grande desafio para a política de saúde nos setores públicos e privados ${ }^{7,8,9,10}$.

As denúncias relacionadas à prática médica obstétrica são frequentes no Conselho Federal de Medicina, representando 30\% do total de queixas ${ }^{11}$. Ademais, a obstetrícia é a especialidade com maior número de ações judiciais, face ao grande número de intercorrências no período pré-natal e nas urgências e emergências no trabalho de parto ${ }^{12}$. Alguns estudos jurisprudenciais evidenciaram que as práticas médicas podem ser pesquisadas a partir de casos concretos julgados pelo Poder Judiciário. A especialidade médica mais demandada foi a obstetrícia $(19,9 \%)$, seguida da cirurgia plástica $(7,8 \%)^{13,14,15,16}$.

As possíveis falhas médicas na obstetrícia podem ser decorrentes de diversas razões, e as sequelas são, em sua maioria, irreversíveis, com danos muitas vezes fatais ${ }^{17}$. Assim, se existe o ato danoso contra a paciente, os médicos em geral estão sujeitos a responderem por seus atos. O primeiro julgamento ocorre na esfera dos

${ }^{7} 5^{\circ}$ RELATÓRIO Nacional de Acompanhamento do ODM - Objetivos de Desenvolvimento do Milênio e a Construção da Agenda pós-2015. Governo do Brasil, 21 maio 2014. Disponível em: <http://www.brasil. gov.br/governo/2014/05/5o-relatorio-nacional-de-acompanhamento-dos-odm-sera-lancado-quarta-21>. Acesso em: 20 ago. 2015.

${ }^{8}$ ANS publica resolução para estimular parto natural na saúde suplementar Detalhes Notícias ANS, 06 jan. 2015. Disponível em: <http://www.ans.gov.br/aans/noticias-ans/consumidor/2718-ministerio-da-saudee-ans-publicam-resolucao-para-estimular-parto-normal-na-saude-suplementar\#sthash.da35g6eA>. Acesso em: 30 mai. 2015.

'LANSKY, S. et al. Birth in Brazil survey: neonatal mortality, pregnancy and childbirth quality of care. Cad. Saude Publica, Rio de Janeiro, v. 30, supl. 1, p. 192-207, 2014. Disponível em: <http://www.scielo.br/pdf/csp/ v30s1/en_0102-311X-csp-30-s1-0192.pdf>. Acesso em: 14 mar. 2016. http://dx.doi.org/10.1590/0102$311 \times 00133213$.

${ }^{10}$ BRASIL. Ministério da Saúde. Secretaria de Políticos de Saúde. Área Técnica de Saúde da Mulher r. Parto, aborto e puerpério: assistência humanizada à mulher. Brasília: Ministério da Saúde, 2001. Disponível em: <http://bvsms.saude.gov.br/bvs/publicacoes/cd04_13.pdf>. Acesso em: 26 out. 2015.

${ }^{11}$ OBSTETRÍCIA - FEBRASGO. Erro médico no dia a dia da ginecologia e obstetrícia. 2014. [20 set. 2014]. Disponível em: <http://www.febrasgo.org.br/site/?p=2019>. Acesso em: 10 abr. 2015.

${ }^{12}$ MOTA, Aline Veras Leite. Análise do Discurso da Jurisprudência do STJ nas indenizações por erro médico: impacto no sistema de saúde. (Dissertação de mestrado). Ribeirão Preto - Faculdade de Medicina de Ribeirão Preto - FMRP/USP, 2015.

${ }^{13}$ NOMURA, R. M. Y.; SEIZO, M.; ZUGAIB, M. O perfil dos médicos denunciados que exercem ginecologia e obstetrícia no Estado de São Paulo. Rev Assoc Med Bras., n. 52, p. 144-147, 2006. Disponível em: <http:// www.scielo.br/pdf/ramb/v52n3/a02v52n3.pdf>. Acesso em: 10 ago. 2015.

${ }^{14}$ GARFINKEL, A. responsabilidade civil por erro médico segundo a jurisprudência do Tribunal de Justiça do Estado de São Paulo (síntese). Revista Direito GV, v. 3, n. 2, p. 37-58, jul./dez. 2007. Disponível em: <http://bibliotecadigital. fgv.br/ojs/index.php/revdireitogv/article/download/35181/33986>. Acesso em: 10 out. 2015.

${ }^{15}$ SPINA, V. P. L.; SÁ, E. C. Perfil das demandas judiciais cíveis por erro médico em Ginecologia e Obstetrícia no Estado de São Paulo. Saúde, Ética \& Justiça, São Paulo, v. 20, n. 1, p. 15-20, 2015. Disponível em: <www. revistas.usp.br/sej/article/download/102820/101109>. Acesso em: 20 abr. 2015.

${ }^{16}$ MOTA, A.V. L. op. cit.

${ }^{17}$ KALLAS FILHO, E. O fato da técnica: excludente da responsabilidade civil do médico. Revista de Direito Sanitário, São Paulo, v. 14, n. 2, p. 137-151, 2013. Disponível em: http://www.revistas.usp.br/rdisan/ article/view/63998>. Acesso em: 10 jul. 2015. 
Conselhos de Medicina, cujas ações se baseiam no Código de Ética Médica ${ }^{18}$. O segundo ocorre na esfera judicial, na qual os médicos estão sujeitos à justiça comum ${ }^{19}$.

Considerando-se o exposto, este artigo apresenta um estudo das demandas julgadas pelo Superior Tribunal de Justiça de 2004 a 2014 acerca de indenizações relacionadas à obstetrícia, considerando-se a prevalência dos danos no momento do parto (cesariana ou natural).

\section{Metodologia}

Trata-se de estudo descritivo e qualitativo de casos jurisprudenciais ${ }^{20}$ cujos dados decorrem do Poder Judiciário ${ }^{21},{ }^{22},{ }^{23},{ }^{24}$. O método utilizado no trabalho foi a busca de decisões judiciais proferidas entre 2004 e 2014 acerca de eventual erro médico na obstetrícia, extraídas do site do STJ. Dentre os principais questionamentos relativos ao estudo, estão: os fatos, as causas e os elementos probatórios das decisões; o tipo de prova levada em consideração; os diplomas legais mais citados nas decisões; os precedentes judiciais mais utilizados; o que e quem influencia os juízes - fatos, provas, doutrina ou jurisprudência, os fundamentos presentes nos tribunais para resolução dos conflitos relacionados à responsabilidade civil do médico obstetra.

A pesquisa de jurisprudência pode ser útil às ciências sociais, não só por motivos linguísticos, mas também porque se trata de fonte do direito relevante diante dos argumentos empregados nos comportamentos das instituições que aplicam o direito em uma sociedade dinâmica e em constante transformação, sendo avaliados os raciocínios jurídicos apresentados nas decisões, suas origens e consequências culturais, econômicas ou políticas ${ }^{25,26}$.

${ }^{18}$ CONSELHO FEDERAL DE MEDICINA. Resolução n. 1931, de 17 de setembro de 2009. Código de Ética Médica. Disponivel em: <http://portal.cfm.org.br/index.php?option=com_content\&view=article\&id=20670:resoluc ao-cfm-no-19312009-\&catid=9:codigo-de-etica-medica-atual\&ltemid=122>. Acesso em: 14 jun. 2015.

${ }^{19}$ OLIVEIRA, D. U. A responsabilidade civil por erro médico. Âmbito Jurídico, v. 11, n. 59, 2008. Disponível em: <http:// www.ambito-juridico.com.br/site/?n_link=revista_artigos_leitura\&artigo_id=3580>. Acesso em: jan. 2015.

${ }^{20}$ YIN, R. K. Estudo de caso: planejamento e métodos. 5. ed. Porto Alegre: Bookman, 2015. p. 1-60.

${ }^{21}$ MAXIMILIANO, C. Hermenêutica e aplicação do Direito. 20. ed. Rio de Janeiro: Forense, 2011. p. 146.

${ }^{22}$ GABARDO, E.; MORETTINI, F. T. R. Institucionalismo e pesquisa quantitativa como metodologia de análises de decisões judiciais. Rev. Fac. Direito UFMG, Belo Horizonte, n. 63, p. 151-180, jul./dez. 2013. Disponível em: <https://www.direito.ufmg.br/revista/index.php/revista/article/view/P.03042340.2013v63p151/1433>. Acesso em: 15 jun. 2018. 10.12818/P.0304-2340.2013v63p151.

${ }^{23}$ SEAWRIGHT, J.; GERRING, J. Case selection techniques in case study research: A Menu of Qualitative and QuantitativeOptions.PoliticalResearchQuarterly,v.61, p.294-308,2008.Disponívelem:<http://blogs.bu.edu/ jgerring/files/2013/06/CaseSelection.pdf>. Acesso em: 22 out. 2015. 10.1177/1065912907313077.

${ }^{24} \mathrm{COACCl}$, T. A pesquisa com acórdãos nas ciências sociais: algumas reflexões metodológicas. Mediações - Revista de Ciências Sociais, v. 18, n. 2, p. 86. Disponivel em: <http://www.uel.br/revistas/uel/index.php/mediacoes/ article/view/17313>. Acesso em 29 set. 2015. http://dx.doi.org/10.5433/2176-6665.2013v18n2p86

${ }^{25}$ FORMA K, G. Os acórdãos do STF como documentos de pesquisa e suas características distintivas. FGV Direito SP Research Paper Series, n. 132, 2015. Disponível em: <https://ssrn.com/abstract=2676292>. Acesso em: 20 set. 2015.

${ }^{26}$ ALVES-MAZZOTTI, A. J.; GEWANDSZNAJNER, F. O. O método nas ciências naturais e sociais: pesquisa quantitativa e qualitativa. 2. ed. São Paulo: Pioneira, 1998. p. 203-206. 
As pesquisas qualitativas podem ser utilizadas com base no estudo jurisprudencial ${ }^{27}$, e sua fonte principal de dados são documentos oficiais do Poder Judiciário. Portanto, esclarece-se que a reiteração das decisões é o que se denomina "jurisprudência", termo que vem do latim jurisprudentia (jus "justo" + prudentia "prudência") e significa o "conjunto de decisões proferidas pelos tribunais nos casos concretos submetidos a seu julgamento"28.

A pesquisa jurisprudencial revela o desenvolvimento do próprio conhecimento científico jurídico ao aproximá-lo de outras ciências sociais. A utilização de uma abordagem institucionalista na metodologia de pesquisa permite identificar o papel do Poder Judiciário como gerador do comportamento dos agentes diretamente envolvidos em suas decisões ${ }^{29}$.

\subsection{Aspectos éticos}

O estudo foi aprovado pelo Comitê de Ética em Pesquisa do Hospital das Clínicas da Faculdade de Medicina de Ribeirão Preto da Universidade de São Paulo (FMRP-USP), com dispensa do Termo de Consentimento Livre e Esclarecido (TCLE), por se tratar de estudo de casos com análise e coleta de dados públicos extraídos de site do Poder Judiciário.

\subsection{Coleta de dados}

Na coleta de dados, optou-se pela decisão dos julgadores do STJ em razão de esta corte resolver questões diretamente relacionadas com as normas federais em última instância e uniformizar o entendimento em caráter nacional a respeito da matéria que é o foco da pesquisa, servindo de parâmetro para fundamentar as demandas judiciais pelos juízes de primeira e segunda instância.

Para que uma demanda seja reapreciada pelo STJ, é necessário que já tenha sido julgada pelo juiz de direito ou juízes federais em primeira instância (a depender da matéria objeto de discussão) e reanalisada pelos tribunais estaduais ou federais em segunda instância. O recurso especial é remédio processual excepcional, com finalidade de submeter ao STJ a apreciação de julgados que estejam permeados por afronta à legislação federal e a tratados internacionais ou por dissídio jurisprudencial entre os tribunais pátrios.

No presente estudo, ocorreram duas etapas de busca das decisões decorrentes do recurso especial. Primeiramente, a seleção das decisões foi realizada em um trabalho

${ }^{27} \mathrm{COACCl}, \mathrm{T}$. op. cit.

${ }^{28}$ YIN, R. K. op. cit.

${ }^{29}$ MAXIMILIANO, C. op. cit. 
acadêmico ${ }^{30}$ cujos resultados apontaram um universo de 90 julgados no período de 2003 a 2013, extraídos do site do STJ e que debatem sobre erros médicos, sendo 12 deles referentes às práticas danosas na obstetrícia. O levantamento dos julgados foi realizado no campo "pesquisa livre", utilizando os seguintes termos: "erro médico"; "médico"; "paciente"; "profissional da saúde"; "dano moral"; "dano material"; "SUS"; "responsabilidade civil" e "indenização por erro médico"; escolheu-se a classe "Recurso Especial" de casos que foram admitidos e julgados pelo STJ.

O critério de exclusão pautou-se pela matéria envolvida acerca da área médica demandada, sendo selecionados apenas os casos da área obstétrica relacionados ao parto, sendo excluídas as demais áreas e causas dos erros médicos durante o período de 2004 a 2014.

Em um segundo momento, foi realizada uma nova pesquisa, com o objetivo de abranger os casos julgados pelo STJ no período de 2004 a 2014. A busca foi realizada no campo "pesquisa livre" com os seguintes termos: "erro médico" e "parto". O resultado da pesquisa encontrou 13 decisões em "Recurso Especial" e em "Agravo Regimental no Agravo em Recurso Especial" que foram apreciadas pelo STJ, quatro das quais constavam na primeira seleção das decisões, o que resultou em um total de 21 julgados. O critério de exclusão pautou-se pelas decisões que não foram apreciadas pelo STJ no período de 2004 a 2014.

A Tabela 1 mostra os casos disponíveis para análise.

\subsection{Análise de dados}

Foram avaliados os objetos de investigação, possibilitando identificar os fundamentos utilizados pelos julgadores e o entendimento externado acerca da matéria debatida. Para comparação de dados, foi empregado o teste de $\mathrm{z}$ ao se tratar de proporções, enquanto que, na comparação de médias, foi empregado o teste $t d e$ Student para amostras independentes. O nível de significância foi de $5 \%(\mathrm{p}<0,05)$.

\section{Resultados}

Na Tabela 2, podem-se observar todos os casos e sua distribuição por ano de julgamento, Estado da Federação de origem, réus do processo e tipo de parto.

O estudo revelou que o estado com mais ações indenizatórias julgadas pelo STJ foi o Rio de Janeiro, com 28,6\% do total, seguido de São Paulo e Minas Gerais, com $14,3 \%(\mathrm{p}>0,05)$, predominando assim a Região Sudeste, porém, sem significância estatística em relação às demais regiões $(p>0,05)$. No tocante aos réus que figuraram no polo passivo das demandas, foi constatado um percentual de $38,1 \%$

\footnotetext{
${ }^{30}$ MOTA, A. V. L. op. cit.
} 
Tabela 1. Casos julgados pelo Superior Tribunal de Justiça no período de 2004 a 2014

\begin{tabular}{clll}
\hline Caso & Tipo de julgado & Número & $\begin{array}{l}\text { Estado } \\
\text { (número de origem) }\end{array}$ \\
\hline 1 & Recurso Especial & 419.026 & DF (2002/0027101-3) \\
2 & Recurso Especial & 820.497 & RJ (2006/0019335-2) \\
3 & AgRg no Agravo de Instrumento & 883.507 & RJ (2007/0053112-4) \\
4 & AgRg no Agravo de Instrumento & 854.005 & MT (2006/0282797-9) \\
5 & Recurso Especial & 1.078 .057 & MG $(2008 / 0168389-1)$ \\
6 & Recurso Especial & 933.067 & MG $(2007 / 0051759-5)$ \\
7 & Recurso Especial & 1.162 .669 & PR (2009/0206930-6) \\
8 & Recurso Especial & 1.174 .490 & MA (2009/0249525-9) \\
9 & Recurso Especial & 1.195 .656 & BA (2010/0094662-0) \\
10 & Recurso Especial & 975.693 & PR (2007/0191871-1) (f) \\
11 & Recurso Especial & 1.173 .058 & DF (2010/0002398-7) \\
12 & Recurso Especial & 1.245 .063 & RJ (2011/0061036-8) \\
13 & Recurso Especial & 1.145 .728 & MG (2009/0118263-2) \\
14 & Recurso Especial & 1.068 .792 & RS (2008/0133064-0) \\
15 & AgRg no Agravo em Recurso Especial & 221.113 & RJ (2012/0177531-9) \\
16 & AgRg no Agravo em Recurso Especial & 163.891 & RJ (2012/0070132-1) \\
17 & AgRg no Agravo em Recurso Especial & 113.057 & RJ (2011/0263696-8) \\
18 & Recurso Especial & 1.289 .679 & RS (2011/0254726-0) \\
19 & AgRg no Agravo em Recurso Especial & 208.343 & SP (2012/0153532-9) \\
20 & AgRg no Agravo em Recurso Especial & 442.266 & SP (2013/0387041-0) \\
21 & AgRg no Agravo em Recurso Especial & 180.480 & SP (2012/0102598-6) \\
\hline
\end{tabular}

Nota: AgRg: Agravo Regimental

Fonte: Superior Tribunal de Justiça

dos médicos e hospitais, comparados ao hospital e ao estado que figuraram individualmente como réus, totalizando $14,3 \%$ cada um deles ( $\mathrm{p}>0,05)$.

Os resultados dos casos julgados pelo STJ obtidos no estudo sugeriram que as supostas falhas obstétricas que originaram as ações indenizatórias ocorreram, em sua maioria, durante a realização de parto natural (71\% dos casos), contra $29 \%$ de cesarianas, observando-se uma predominância significativa daqueles $(\mathrm{p}<0,05)$.

Na Tabela 3, observam-se os danos e suas respectivas causas decorrentes de cesariana, considerando-se a natureza jurídica do hospital.

No primeiro caso, foi constatado pela perícia que, na cirurgia realizada pela médica nas dependências do hospital, com utilização de serviços e equipamentos deste, foi esquecido corpo estranho no organismo da autora, resultando processo inflamatório e necessidade de extração do corpo estranho. 
Tabela 2. Comparação por ano de julgamento, estado do ajuizamento da ação, os réus que figuraram no polo passivo e o tipo de parto realizado.

\begin{tabular}{lllll}
\hline Caso & $\begin{array}{l}\text { Ano do } \\
\text { julgamento }\end{array}$ & Estado & Réu (s) & Tipo de parto \\
\hline 1 & 2004 & DF & Médica e hospital & Cesariana \\
2 & 2006 & RJ & Município: Rio de Janeiro & Natural \\
3 & 2007 & RJ & Município: Rio de Janeiro & Natural \\
4 & 2008 & MT & Hospital e médicos & Cesariana \\
5 & 2009 & MG & Hospital & Natural \\
6 & 2010 & MG & Hospital e médico & Natural \\
7 & 2010 & PR & Hospital & Cesariana \\
8 & 2010 & MA & Estado & Cesariana \\
9 & 2011 & BA & Hospital e médico & Natural \\
10 & 2011 & PR & Médica & Natural \\
11 & 2011 & DF & Médica e hospital & Natural \\
12 & 2011 & RJ & União e hospital militar & Natural \\
13 & 2011 & MG & Hospital & Natural \\
14 & 2011 & RS & Município: Porto Alegre & Natural \\
15 & 2012 & RJ & Município: Rio de Janeiro e médicos & Natural \\
16 & 2012 & RJ & Município: Rio de Janeiro e médicos & Cesariana \\
17 & 2012 & RJ & Médica & Natural \\
18 & 2013 & RS & Universidade Federal de Santa Maria & Cesariana \\
19 & 2014 & SP & Hospital & Natural \\
20 & 2014 & SP & Fundação Santa Casa & Natural \\
21 & 2014 & SP & Hospital e médica & Natural \\
\hline
\end{tabular}

Fonte: Superior Tribunal de Justiça

Tabela 3. Associação de cesariana às causas dos danos e às sequelas sofridas, e tipo de hospital, se público ou privado.

\begin{tabular}{llll}
\hline Caso & Causas dos danos & Danos & Hospital \\
\hline 1 & $\begin{array}{l}\text { Esquecimento de compressa cirúrgica } \\
\text { no organismo da parturiente }\end{array}$ & $\begin{array}{l}\text { Mãe sofreu retirada da trompa } \\
\text { esquerda; transfusão } \\
\text { de sangue; drenagem }\end{array}$ & Privado \\
2 & $\begin{array}{l}\text { Esquecimento de compressa cirúrgica } \\
\text { no organismo da parturiente }\end{array}$ & $\begin{array}{l}\text { Mãe sofreu septicemia; retirada parcial } \\
\text { do útero; utilizou bolsa de colostomia; } \\
\text { perda auditiva e cicatrizes }\end{array}$ & Público \\
3 & Prescrição irregular de medicação & $\begin{array}{l}\text { Perda do filho e extração } \\
\text { do útero materno }\end{array}$ & Privado \\
4 & $\begin{array}{l}\text { Demora na realização do parto - } \\
\text { Sofrimento fetal }\end{array}$ & $\begin{array}{l}\text { Nascituro sofreu paralisia cerebral tipo } \\
\text { hemiparesia à esquerda }\end{array}$ & Público \\
5 & $\begin{array}{l}\text { Falta de material adequado para } \\
\text { procedimento cirúrgico } \\
\text { Negligência do anestesista }\end{array}$ & $\begin{array}{l}\text { hipóxico-isquêmica } \\
\text { Mãe sofreu parada cardiorrespiratória e e } \\
\text { coma irreversível durante o parto }\end{array}$ & Público \\
\hline
\end{tabular}

Fonte: Superior Tribunal de Justiça 
No caso 2, a ação foi julgada procedente em virtude dos danos físicos, estéticos, morais e materiais causados à parturiente, sendo que as indenizações somaram $\mathrm{R} \$ 1,275$ milhão. A vítima submeteu-se a cesariana em maternidade pública estadual, ocasião em que foi esquecida uma compressa cirúrgica em seu abdômen, ocasionando septicemia. Em decorrência desse quadro, foi necessária a realização de histerectomia, a vítima utilizou colostomia por oito meses e ainda perdeu parcialmente a capacidade auditiva. Neste caso, o julgamento concluiu que a retirada do útero impossibilitou a mulher de procriar e afetou o direito de livre decisão do casal, causando dano moral também ao marido. Resultou ainda dano moral ao filho recém-nascido, por não ter os cuidados necessários de sua genitora, inclusive não tendo o direito ao aleitamento materno. Foram fixados os valores de $\mathrm{R} \$ 400$ mil a título de dano moral e $\mathrm{R} \$ 800$ mil a título de dano estético para a mãe; $\mathrm{R} \$ 50$ mil por danos para o marido e $\mathrm{R} \$ 25$ mil para o filho.

No terceiro caso, a prescrição irregular de medicamento provocou inércia uterina, resultando no parto prematuro. No hospital, foi prescrito pelo médico um anti-inflamatório não hormonal (diclofenaco sódico), cuja bula observava como contraindicação o risco de efeitos colaterais em gestantes, sobretudo a possibilidade de ocasionar inércia uterina e/ou fechamento prematuro do canal arterial, acarretando a morte fetal e a extração do útero da parturiente.

No caso 4, a ação foi julgada procedente em primeira e segunda instâncias, mas o STJ reformou a decisão, excluindo a União sob o argumento de que, pela demora no atendimento ao parto no SUS, não se pode responsabilizá-la. O julgamento pautou-se em diversos acórdãos análogos, sendo predominante o entendimento de que, nos casos envolvendo o SUS, a União não tem legitimidade para responder por eventuais danos causados pelos profissionais e instituições de saúde vinculados.

No quinto caso, a prova pericial concluiu que houve nexo causal, por falta de material necessário e imprescindível à boa condução do parto; a criança apresenta sequelas graves de asfixia hipóxico-isquêmica, ocorrida durante o procedimento; o menor necessita de acompanhamento multidisciplinar permanente em instituições especializadas. Há necessidade contínua de neuroestimulação; acompanhamento com fisioterapeuta; além de órteses para os membros inferiores. No caso em exame, 0 Tribunal, ao considerar as circunstâncias do caso concreto, determinou indenização de $\mathrm{R} \$ 80$ mil para o montante de $\mathrm{R} \$ 100$ mil por danos morais.

No sexto caso, embora a médica obstetra tenha alertado em duas ocasiões a médica anestesista acerca da falta de oxigenação e diminuição do sangramento da paciente, os procedimentos adotados não foram suficientes para impedir o coma irreversível sofrido pela parturiente. Diante da situação do sofrimento fetal, o laudo pericial afirmou que a atuação de médicos residentes (menor experiência) em procedimentos de maior complexidade exige o acompanhamento de 
médico especialista do corpo clínico do hospital. O perito concluiu ainda que o ocorrido na gestante deveu-se a complicações anestésico-cirúrgicas, restando evidenciada a negligência do hospital em não disponibilizar um profissional experiente e capacitado.

$\mathrm{Na}$ Tabela 4, são apresentados os casos referentes a partos normais, focando os danos, sequelas e natureza jurídica do hospital de origem.

A principal causa dos danos durante a realização do parto natural foi o período expulsivo prolongado, seguida pelos traumatismos como segunda causa.

Tabela 4. Associação do parto natural às causas dos danos e às sequelas sofridas, e tipo de hospital, se público ou privado.

\begin{tabular}{|c|c|c|c|}
\hline Caso & Causas dos danos & Danos & Hospital \\
\hline 7 & Demora na realização do parto & $\begin{array}{l}\text { Nascituro sofreu sequelas neurológicas } \\
\text { irreversíveis }\end{array}$ & Público \\
\hline 8 & Conduta culposa do médico & Óbito fetal & Público \\
\hline 9 & Traumatismo & Nascituro sofreu paralisia cerebral & Privado \\
\hline 10 & $\begin{array}{l}\text { Ausência de assistência do médico } \\
\text { obstetra / Posição incomum do feto }\end{array}$ & Sequelas motoras irreversíveis & Privado \\
\hline 11 & Demora na realização do parto & $\begin{array}{l}\text { Nascituro sofreu sequelas irreversíveis } \\
\text { (paraplegia) }\end{array}$ & Privado \\
\hline 12 & Período expulsivo prolongado & $\begin{array}{l}\text { Nascituro sofreu lesões corporais } \\
\text { e neurológicas }\end{array}$ & Privado \\
\hline 13 & Anóxia decorrente de tocotraumatismo & $\begin{array}{l}\text { Nascituro sofreu sequelas } \\
\text { neurológicas irreversíveis }\end{array}$ & - \\
\hline 14 & Demora na realização do parto & Nascituro sofreu sequelas irreversíveis & Privado \\
\hline 15 & Ausência de pediatra no parto & $\begin{array}{l}\text { Nascituro sofreu sequelas } \\
\text { neurológicas irreversíveis }\end{array}$ & Público \\
\hline 16 & Asfixia fetal no parto & $\begin{array}{l}\text { Encefalopatia hipóxico-isquêmica } \\
\text { neonatal }\end{array}$ & Privado \\
\hline 17 & $\begin{array}{l}\text { Parto natural (posição inadequada } \\
\text { do feto) }\end{array}$ & $\begin{array}{l}\text { Nascituro sofreu sequelas } \\
\text { neurológicas e motoras }\end{array}$ & Público \\
\hline 18 & Atendimento inadequado pós-parto & $\begin{array}{l}\text { Nascituro sofreu distócia no } \\
\text { ombro e asfixia }\end{array}$ & - \\
\hline 19 & Traumatismo & $\begin{array}{l}\text { Nascituro sofreu sequela motora } \\
\text { irreversível }\end{array}$ & Privado \\
\hline 20 & $\begin{array}{l}\text { Choque anafilático da parturiente } \\
\text { (medicação irregular) }\end{array}$ & $\begin{array}{l}\text { Nascituro sofreu sequelas neurológicas } \\
\text { no feto - Mãe sofreu remoção do útero }\end{array}$ & Público \\
\hline 21 & Demora na realização do parto & Óbito fetal & Privado \\
\hline
\end{tabular}

Fonte: Autora 
As sequelas irreversíveis ocorridas nos recém-nascidos predominaram como os danos mais recorrentes, à frente dos óbitos fetais e dos danos irreversíveis sofridos pela mãe, sendo que a maioria dos partos normais ocorreu em hospitais privados.

Nos casos relacionados à demora na realização do parto e ao período expulsivo prolongado (casos $7,11,12,14,21$ ), houve relatos de que o erro consistiu na conduta negligente do médico em não optar pela cesariana, na falta de acompanhamento da frequência cardíaca do feto e na retirada do profissional da sala de parto no momento crítico da expulsão do recém-nascido. Em um dos casos, foi demonstrada a negligência do hospital, que se manteve inerte e não acionou seus prepostos para realizar o parto emergencial na mãe da vítima, iniciado tardiamente pela médica que utilizava a estrutura do estabelecimento hospitalar; assim, o hospital deve responder solidariamente pelos danos causados à criança, que nasceu com lesões de natureza física e neurológicas irreversíveis. Em outro caso, houve falha na prestação do serviço médico hospitalar, que deixou de tomar as precauções necessárias e urgentes de forma a impedir um trabalho de parto tardio, e, consequentemente, sofrimento e sequelas irreversíveis no feto, que veio a óbito posteriormente.

Dois casos relacionados à demora na realização do parto foram julgados improcedentes (casos 7 e 11). No caso 7, o laudo foi taxativo ao concluir que os médicos atuaram com todas as precauções necessárias, incluindo a realização do procedimento que se mostrava mais adequado, e que era impossível prever, tampouco prevenir, o dano sobrevindo. Destarte, a conclusão da perícia comprovou que a obrigação de meio da equipe médica foi cumprida e o resultado, ainda que não esperado, não revela desacerto profissional. No caso 11, o STJ reformou as decisões de primeiro e segundo grau. Feita perícia, o médico perito não pôde atestar que a patologia apresentada pelo filho da autora era consequência da negligência do médico requerido. A perícia foi clara quanto à ausência de negligência, referindo que houve emprego da melhor técnica e diligência entre as possibilidades de que dispõe o profissional no seu meio de atuação, em auxílio do paciente. Não se pode olvidar de que, mesmo que os profissionais envolvidos empreguem toda sua diligência no ato, ainda assim podem advir reações imprevisíveis e situações inesperadas.

No tocante aos casos relacionados aos traumatismos, duas ações foram julgadas improcedentes (casos 13 e 19). No caso 13, foi demonstrado nos laudos periciais médicos que a lesão não decorreu de um resultado advindo de um defeito na prestação do serviço, mas sim de evento inesperado e imprevisível durante o procedimento. As perícias realizadas demonstraram que não houve má condução do trabalho de parto, e sim que o ocorrido com o complexo mãe-filha foi objeto de uma fatalidade: o parto se iniciou como o habitual e se tornou excessivamente laborioso devido à distócia de ombro da recém-nascida, causando sequelas permanentes. No caso 19, o perito esclareceu que não é possível dizer qual foi a causa da síndrome 
neurológica do autor, a qual pode decorrer não apenas do alegado traumatismo no parto, mas também de hipertensão gestacional, insuficiência placentária ou infecção. Assim, baseado em minucioso exame das provas constantes dos autos, concluiu o acórdão não haver prova de nexo causal e de culpa da médica.

A realização do parto natural em posição inadequada do feto ocorreu em dois casos (casos 17 e 18). No caso 17, o julgado concluiu pela exclusão dos médicos, em razão da correta conduta praticada, e pela manutenção do Município pela falha na prestação do serviço por um de seus agentes (enfermeira obstetriz). Mesmo cientes de que a autora ainda não se encontrava encaixada na posição adequada, optaram por realizar o parto natural através do uso do fórceps, quando seria indicada a cesariana; advindo dessa decisão, houve sérios danos à autora, que nasceu sem movimentos e necessitou ser reanimada, com asfixia grave, edema cerebral e hidrocefalia. Contudo, concluiu o expert do juízo que o uso do fórceps não contribuiu para o estado de saúde atual da menor, ainda que não tenha havido erro técnico durante sua aplicação, porque ausentes sinais de traumatismo fetal por sua utilização; salientou que, na realidade, os danos à menor foram ocasionados pela indicação tardia, ou seja, o que ocasionou a interrupção da oxigenação encefálica foi o hiato temporal ( 1 hora e 13 minutos) entre a parada de progressão em plano III de Hodge e a extração final do concepto.

$\mathrm{Na}$ Tabela 5, podem ser observados os resultados do julgamento, a natureza da indenização e o valor monetário da condenação, considerando-se as provas produzidas.

Os dados demonstram que os danos morais e materiais foram as indenizações mais pleiteadas nas demandas, face à predominância das sequelas irreversíveis, enquanto que as indenizações morais foram constatadas em cinco casos. A prova pericial se destaca como principal meio de prova, em virtude de os casos demandarem maior especificação técnica de outros médicos, cuja função é examinar e elaborar de forma rigorosa os elementos trazidos aos autos (fato, dano, provas documentais etc.). A prova documental já trazida aos autos, antes da realização da perícia, passa a ser relevante quando produzida na fase inicial do processo.

A maioria das decisões foi julgada procedente em face do réu, com um percentual de $61,9 \%$ dos casos. Interessante concluir que $23,8 \%$ das ações foram julgadas improcedentes na decisão de origem ou revertidas pelos Tribunais, mesmo diante da prova do dano ocorrido. Em todos os casos, a improcedência foi suscitada em razão da ausência do nexo causal entre o dano e a conduta do agente. Nesses casos, as provas realizadas nos autos foram essenciais para tal desfecho.

No caso que resultou no cerceamento de defesa, os autos retornaram à origem para nova produção de prova. O STJ entendeu que, em matéria de responsabilidade civil, quando a parte pretende provar a culpa exclusiva de terceiro, não se pode aceitar a simples presunção de que a participação da equipe auxiliar 
Tabela 5. Distribuição do tipo de prova produzida frente à procedência ou improcedência da ação, assim como a natureza da indenização pleiteada e o valor da condenação.

\begin{tabular}{|c|c|c|c|}
\hline Prova produzida & $\begin{array}{l}\text { Resultado do } \\
\text { julgamento }\end{array}$ & $\begin{array}{l}\text { Natureza da } \\
\text { indenização }\end{array}$ & Valor da condenação \\
\hline Documental & $\begin{array}{l}\text { Cerceamento de } \\
\text { defesa - Retorno } \\
\text { à origem }\end{array}$ & Moral e material & - \\
\hline Documental e pericial & Procedência & Moral & $\begin{array}{l}\mathrm{R} \$ 180 \text { mil (moral) e } 3 \text { salários } \\
\text { mínimos (pensão vitalícia) }\end{array}$ \\
\hline $\begin{array}{l}\text { Documental e } \\
\text { testemunhal }\end{array}$ & Procedência & Moral e material & $\mathrm{R} \$ 40 \mathrm{mil}$ \\
\hline $\begin{array}{l}\text { Pericial, documental e } \\
\text { testemunhal }\end{array}$ & Procedência & Moral & - \\
\hline $\begin{array}{l}\text { Pericial, documental e } \\
\text { testemunhal }\end{array}$ & Procedência & Moral e material & $\mathrm{R} \$ 14.400,00$ \\
\hline Testemunhal e pericial & Procedência & Moral e material & $\begin{array}{l}\mathrm{R} \$ 50 \text { mil (moral) e } 2 \text { salários } \\
\text { mínimos (pensão vitalícia) }\end{array}$ \\
\hline Documental & $\begin{array}{l}\text { Ilegitimidade } \\
\text { passiva União }\end{array}$ & $\begin{array}{l}\text { Moral, material e } \\
\text { estético }\end{array}$ & - \\
\hline Documental & Procedência & Moral e material & $\begin{array}{l}\mathrm{R} \$ 400 \text { mil (estético); } \mathrm{R} \$ 800 \\
\text { mil (moral) e quatro salários } \\
\text { mínimos (material) }\end{array}$ \\
\hline Pericial & Procedência & Moral e material & $\begin{array}{l}\mathrm{R} \$ 500 \text { mil (moral) e } \mathrm{R} \$ \\
136.250,00 \text { (material) }\end{array}$ \\
\hline Pericial & Improcedência & Moral e material & - \\
\hline Testemunhal e pericial & Procedência & Moral e estético & $\begin{array}{l}\mathrm{R} \$ 200 \text { mil (moral); } \mathrm{R} \$ \\
46.729,00 \text { (material) e } 10 \\
\text { salários mínimos (pensão) }\end{array}$ \\
\hline $\begin{array}{l}\text { Documental e } \\
\text { testemunhal }\end{array}$ & Procedência & Moral e material & 200 salários mínimos (moral) \\
\hline Pericial & Procedência & Moral & $\mathrm{R} \$ 76$ mil (moral) \\
\hline Documental & $\begin{array}{l}\text { Extinção pela } \\
\text { prescrição }\end{array}$ & Moral & - \\
\hline Pericial & Procedência & Moral e material & $\begin{array}{l}\mathrm{R} \$ 100 \text { mil (moral) e despesas } \\
\text { médicas a serem liquidadas }\end{array}$ \\
\hline Pericial & Procedência & Moral e material & $\begin{array}{l}\mathrm{R} \$ 100 \text { mil (moral) e dois } \\
\text { salários mínimos (pensão) }\end{array}$ \\
\hline Pericial & Improcedência & Moral & - \\
\hline Pericial e testemunhal & Procedência & $\begin{array}{l}\text { Moral, material e } \\
\text { estético }\end{array}$ & $\begin{array}{l}\mathrm{R} \$ 100 \text { mil (moral) e um salário } \\
\text { mínimo (pensão) }\end{array}$ \\
\hline Pericial e testemunhal & Improcedência & Moral & - \\
\hline Pericial e testemunhal & Procedência & Moral & $\begin{array}{l}\mathrm{R} \$ 100 \text { mil (moral) e um salário } \\
\text { mínimo (pensão) }\end{array}$ \\
\hline Pericial e testemunhal & Procedência & Moral & $\begin{array}{l}300 \text { salários mínimos (moral) - } \\
\text { Improcedente dano material }\end{array}$ \\
\hline
\end{tabular}

Fonte: Autora 
do hospital seja responsável se o fato em si foi o esquecimento de corpo estranho durante a cirurgia, já que a própria cirurgiã afirma que os serviços do hospital foram adequados e satisfatórios. O que não parece razoável em tal circunstância é afastar a oportunidade de o hospital produzir prova para sustentar sua alegação de não ter sido responsável pelo evento danoso.

Os valores das condenaçãoes acerca da indenização moral e/ou estética chegaram a quantias altas, sendo que a média dos valores dessa natureza foi de R $\$ 300$ mil. Os danos materiais são fixados mediante a incapacidade física decorrente das sequelas irreversíveis constatada na prova pericial, sendo que a fixação foi apurada com base no salário mínimo. A condenação aos danos materiais chegou a até 10 salários mínimos mensais, conforme comprovada a hipossuficiência do paciente e as sequelas causadas.

\section{Discussão}

Em que pese as recentes pesquisas realizadas no Brasil demonstrarem que a cesariana ofereça maiores riscos para a parturiente e o feto ${ }^{31,32,33,34,35}$, os resultados obtidos no levantamento revelam que os danos fetais resultantes em sequelas irreversíveis no nascituro foram recorrentes nos casos relacionados ao parto natural. Os casos analisados sugerem fortemente a prevalência das sequelas causadas nos nascituros durante o pré-parto e o parto natural, resultando em 13 ocorrências duas delas com desfecho em óbito -, ao passo que em nenhum dos casos analisados foram constatadas sequelas ou danos na parturiente.

Em razão da ocorrência de danos físicos, cerebrais, motores e cognitivos definitivos que geram incapacidade funcional no nascituro, a condenação em danos materiais foi prevalente, chegando a 10 salários mínimos mensais a título de pensão vitalícia. Isso porque, em várias decisões analisadas, os julgadores se pautaram nas consequências geradas pela incapacidade absoluta e definitiva da criança lesada. Referidos danos impedem que os nascituros vivam normalmente, pois são muitas vezes incapazes de exercerem no futuro qualquer atividade laborativa, sempre dependendo de familiares e de equipe multidisciplinar de profissionais para assisti-los.

Observa-se hoje que a cesariana é considerada um procedimento cirúrgico comum em todo o mundo. Alguns dados norte-americanos e europeus revelaram

\footnotetext{
${ }^{31}$ NASCER no Brasil. op. cit.

${ }^{32}$ VASCONCELLOS, M.T.L. et al. op. cit.

${ }^{33}$ KORNACKA, M. K.; KUFEL, K. Neonatal outcome after cesarean section. Ginekol Pol., v. 83, n. 8, p. 612-617, Aug. 2011. 10.1097/AOG.0b013e3181a66d57.

${ }^{34}$ COX, K. J.; KING, T. L. Preventing primary cesarean births: midwifery care. Clin Obstet Gynecol., v. 58, n. 2, p. 282-293, Jun. 2015. 10.1097/GRF.0000000000000108. Acesso em: 14 jun. 2015.

${ }^{35}$ MARTINS-COSTA, S.; MARTINS-COSTA, G.; RAMOS, J. G. L. Parto, encefalopatia neonatal e paralisia cerebral. Femina, v. 37, n., 4, p. 223-227, abr. 2009. Disponível em: <http://www.febrasgo.org.br/site/wp-content/ uploads/2013/05/Femina-v37n4-p223.pdf>. Acesso em: 24 fev. 2016.
} 
aumento de gestações resolvidas por cesariana. As razões incluem o número crescente de indicações médicas e de pedidos das mulheres grávidas. Isso porque a cesárea eletiva pode diminuir o risco de sofrimento fetal, aspiração de mecônio e ferimentos durante o trabalho. Todavia, foi constatado que a cesariana gera um fator de maior risco de insuficiência respiratória no curso de taquipneia transitória do recém-nascido, síndrome da angústia respiratória e hipertensão pulmonar, tanto para os nascituros a termo quanto para os prematuros lactentes. Como consequência, a criança necessita de uma estadia prolongada na unidade de terapia intensiva, em conjunto com procedimentos médicos avançados e muitas vezes caros, tais como ventilação mecânica (muitas vezes de alta frequência), tratamento com óxido nítrico e oxigenação por membrana extracorpórea ${ }^{36}$.

Dessa forma, a Associação Norte-Americana de Obstetras e Ginecologistas e a Associação Europeia de Medicina Perinatal recomendam que a cesariana seja indicada apenas para partos realizados a partir de 39 semanas de gestação, de preferência após as contrações uterinas iniciadas e a avaliação da maturidade pulmonar. Isso inclui também casos de cesarianas eletivas realizadas devido a cesarianas anteriores, que são as razões mais frequentes para o procedimento de repetição. As recomendações também restringem as indicações de cesariana aos casos de prematuridade significativa, o que, por sua vez, está conectado a indicações mais restritas para reanimação de prematuros extremos e bebês com extremo baixo peso ao nascer ${ }^{37}$.

Estudos norte-americanos ${ }^{38,39}$ apontaram que a incidência de cesariana é alarmante e associada às altas taxas de morbidade materna e fetal. Assim, estratégias para prevenir cesariana em gestações de baixo risco são necessárias em mulheres nulíparas, a termo e com feto único. Tais estudos também abordam algumas práticas baseadas em evidências que podem ser utilizadas durante o parto para evitar a cesariana primária, incluindo a paciência da parturiente durante o processo do parto, a ausculta intermitente, o suporte de trabalho contínuo, as posições verticais e a livre mobilidade e as práticas de trabalho em segundo plano, como manejar a rotação do feto. Esses cuidados obstétricos podem, potencialmente, reduzir as taxas de cesariana primária.

Por outro lado, o parto natural pode ser considerado de maior risco no que tange aos traumas físicos, tanto maternos quanto fetais. Sempre houve discussão de se o parto, em especial o trauma de parto, é uma causa frequente de paralisia cerebral no nascituro, tendo como consequência a encefalopatia neonatal. Essa anomalia

\footnotetext{
${ }^{36} \mathrm{COX}$, K. J.; KING, T. L. op. cit.

${ }^{37}$ KORNACKA, M. K.; KUFEL, K. op. cit.

${ }^{38}$ Id. Ibid.

${ }^{39} \mathrm{COX}$, K. J.; KING, T. L. op. cit.
} 
foi estabelecida em meados do século XIX e, segundo alguns estudos, permanece incontestada até os dias atuais ${ }^{40,41,42}$.

Ocorre que uma pesquisa evidenciou que o aumento nas taxas de cesariana não acompanhou uma redução proporcional nos casos de paralisia cerebral nas crianças nascidas decorrentes do parto natural. Foi realizada uma revisão da literatura sobre a patogênese da encefalopatia neonatal e da paralisia cerebral e suas relações com o período intraparto. Em 1998, o Western Australia Case-control Study demonstrou que muitos casos de encefalopatia neonatal não resultam em paralisia cerebral e que a incidência de encefalopatia neonatal atribuível a eventos intraparto, na ausência de qualquer outra anormalidade pré-concepcional ou anteparto, é estimada como sendo de aproximadamente $1,5 / 10$ mil crianças ${ }^{43,44}$.

Do mesmo modo, tem sido demonstrado que as causas de encefalopatia neonatal são heterogêneas e podem decorrer de outros fatores, tanto pré-concepcionais como antenatais. Alguns estudos observaram que não há evidência de hipóxia intraparto em mais de $70 \%$ dos casos de encefalopatia neonatal e que a hipóxia intraparto isolada é responsável por somente $4 \%$ dos casos de encefalopatia grave em recém-nascidos. Além disso, a hipóxia intraparto pode estar sobreposta a fatores de risco pré-concepcionais ou anteparto com dano pré-existente em $25 \%$ dos $\operatorname{casos}^{45,46,47}$. Portanto, as evidências atuais dão embasamento para o conceito de que a paralisia cerebral deve ser o resultado de uma combinação de fatores, que incluem predisposição genética e fatores desencadeadores, os quais podem atuar no ambiente tanto intra como extrauterino ${ }^{48,49}$.

Em que pese as causas frequentes de paralisia cerebral na infância tenham sido, por muito tempo, relacionadas ao nascimento, particularmente no período intraparto, uma vez que as evidências científicas não dessem a sustentação necessária, suas causas são múltiplas e frequentemente desconhecidas, podendo ter sua gênese durante os períodos pré-concepcional, pré-natal, intraparto ou após o nascimento. Antes de culpar o parto ou seu atendimento como causador de dano

\footnotetext{
${ }^{40}$ MARTINS-COSTA, S.; MARTINS-COSTA, G.; RAMOS, J. G. L.

${ }^{41}$ CRUZ, A. C. S.; CECCON, M. E. J. Prevalência de asfixia perinatal e encefalopatia hipóxico-isquêmica em recém-nascidos de termo considerando dois critérios diagnósticos. Rev Bras Crescimento Desenvolv Hum., v. 20, p. 302-316, 2010. Acesso em: <http://pepsic.bvsalud.org/pdf/rbcdh/v20n2/13.pdf>. Acesso em: 25 mar. 2016. http://dx.doi.org/10.7322/jhgd.19968.

${ }^{42}$ TAKAZONO, P.S.; GOLIN, M.O. Asfixia perinatal: repercussões neurológicas e detecção precoce. Neurociencias, v. 21, n. 1, p. 108-117, 2013. Disponível em: <http://www.revistaneurociencias.com.br/edicoes/2013/ RN2101/revisao2101/761revisao.pdf>. Acesso em: fev. 2016. 10.4181/RNC.2013.21.761.10p.

${ }^{43}$ CRUZ, A. C. S.; CECCON, M. E. J. op. cit.

${ }^{44}$ TAKAZONO, P.S.; GOLIN, M.O. op. cit.

${ }^{45}$ COX, K. J.; KING, T. L. op. cit.

${ }^{46}$ MARTINS-COSTA, S.; MARTINS-COSTA, G.; RAMOS, J. G. L. op. cit.

${ }^{47}$ CRUZ, A. C. S.; CECCON, M. E. J. op. cit.

${ }^{48}$ Id. Ibid.

${ }^{49}$ TAKAZONO, P.S.; GOLIN, M.O. op. cit.
} 
cerebral permanente, deve ser considerada a presença de critérios cientificamente aceitos que definam um evento hipóxico agudo intraparto como suficiente ou não para causar paralisia cerebral ${ }^{50,51,52,53}$.

Ainda que a análise investigativa com base na jurisprudência não alcance de maneira profunda todos os pontos da medicina científica, por se tratar de casos individualmente julgados que levam em conta os fatos e as provas realizadas quando da investigação, seus fundamentados trazem parâmetros importantes que sugerem novos estudos a partir das informações e dos dados levantados.

Com a investigação dos 21 casos julgados pelo ST], foi possível observar que, embora exponha a realidade de um número ínfimo de pacientes que sofreram danos no momento puerperal, os resultados foram ao encontro de algumas das pesquisas científicas aqui expostas ${ }^{29,30,31}$. Além disso, foi possível constatar que as principais causas dos danos decorrem, especialmente, das várias deficiências estruturais das organizações públicas e privadas presentes diariamente nos centros de saúde, que prestam os serviços maternos e fetais de forma ineficiente.

Os resultados do trabalho demonstraram que, nos 15 casos relacionados ao parto natural, ocorreram diversos eventos danosos nos nascituros; apenas uma das mães sofreu remoção do útero, em virtude de aplicação de medicação irregular (caso 20). Isso demonstra um risco maior ao feto durante o parto natural, conforme, inclusive, constatado em pesquisas científicas ${ }^{29,30,31}$.

Com efeito, observou-se que os hospitais privados predominaram nos atendimentos relacionados ao parto natural (casos 9,10,11,12,14,16,19,21). Sob esse prisma, foi possível constatar que os profissionais de saúde e as instituições hospitalares foram condenados de forma solidária pelos atos danosos praticados. Foram unânimes os posicionamentos dos julgadores do STJ quanto aos atos técnicos praticados de forma defeituosa pelos profissionais da saúde vinculados de alguma forma ao hospital, respondendo solidariamente a instituição hospitalar e o profissional responsável, quando apurada sua culpa profissional mediante prova pericial.

Os julgadores entenderam que a responsabilidade seria do médico que atuou diretamente no parto e também do hospital, ainda que não fosse empregador do profissional obstetra. Sobretudo, a responsabilidade pautou-se na obrigação do hospital de zelar pela qualificação e capacidade dos profissionais que atuam em suas dependências, bem como supervisionar os serviços prestados em seu estabelecimento.

\footnotetext{
${ }^{50}$ COX, K. J.; KING, T. L. op. cit.

${ }^{51}$ MARTINS-COSTA, S.; MARTINS-COSTA, G.; RAMOS, J. G. L. op. cit.

${ }^{52}$ CRUZ, A. C. S.; CECCON, M. E. J. op. cit.

${ }^{53}$ TAKAZONO, P.S.; GOLIN, M.O. op. cit.
} 
Dos centros de saúde que atenderam os partos cesáreos, a maior parte era hospitais públicos. Ao se analisarem os resultados e as principais causas dos danos - tais como esquecimento de objetos cirúrgicos; prescrição irregular de medicamentos; falta de material adequado para procedimento cirúrgico; despreparo dos profissionais (médicos e enfermeiros), dentre outras -, conclui-se que muitas ocorrências poderiam ter sido evitadas, a começar pela infraestrutura ineficiente dos hospitais, tanto públicos como privados: escassez de investimentos nos serviços mais básicos e nos materiais necessários para o desenvolvimento das atividades, insuficientes tecnologias em saúde e até mesmo ausência de incentivo à qualificação dos profissionais que atuam na área (pelo que ficou evidente nos julgados, com a constatação de culpa e despreparo profissional comprovados nas provas periciais realizadas).

Veja-se que a má prática nos procedimentos médicos abrange elementos que podem ser extraídos da conduta culposa, ou seja, a conduta voluntária com resultado involuntário, a previsão ou previsibilidade e, por fim, a ausência de cuidado, cautela e diligência, sem a devida atenção às regras técnicas pertinentes ao exercício profissional. Diante das intercorrências, os danos maternos e fetais foram graves e irreversíveis, especialmente no que tange às sequelas ${ }^{5,6,27,28}$ : retirada da trompa; retirada do útero; perda auditiva; septicemia; dentre outras.

Independentemente do tipo de parto realizado, o ponto forte da presente pesquisa é reconhecer a importância do tema, mostrando os resultados e fatores relacionados à prática médica na obstetrícia durante a realização seja de parto natural, seja de cesariana. É fundamental formular medidas no sentido de fomentar e discutir as melhores práticas dos profissionais da saúde obstétrica, sobretudo a fim de minimizar os riscos e proporcionar maior segurança à vida e à saúde materna e fetal. O estudo utilizou dados e informações concretos acerca das ações judiciais que resultaram em indenizações relacionadas ao parto realizado, $o$ que sem dúvida leva a contribuir e ampliar a possibilidade de comparações com resultados em nível nacional.

As limitações do trabalho referem-se ao desenho observacional, que inviabiliza a identificação ampla do pensamento do Judiciário brasileiro acerca das indenizações em obstetrícia, assim como dificulta uma compreensão maior sobre aspectos socioculturais da população, além de aspectos relacionados à formação médica em obstetrícia que interferem na escolha pelo tipo de parto preferencial pelas mulheres brasileiras e suas famílias e o papel do obstetra nesse momento. Os resultados obtidos no estudo revelam tão somente o entendimento do STJ, cujo critério de seleção das decisões limita a abrangência do número de casos disponíveis para análise, uma vez que as matérias submetidas aos tribunais superiores não podem revolver fatos e provas. Sem contar que, como a maioria das decisões transita em julgado em primeira e segunda instâncias, muitas vezes não são submetidas ao reexame das instâncias superiores. 


\section{Considerações finais}

O estudo demonstra a necessidade de identificação e implantação de intervenções efetivas na minimização dos riscos que geram danos e sequelas no momento puerperal, assim como a redução da mortalidade materna durante o parto e a integridade à vida e saúde do nascituro. Tais medidas devem ser prioridades das instituições públicas e privadas e da própria sociedade.

Em que pese o entendimento do STJ reflita uma restrita parcela das ações "objeto da pesquisa", as informações e os dados levantados podem servir de parâmetro para os demais casos em instâncias inferiores, uma vez que esta corte uniformiza e pacifica as questões relativas à lei federal. Dessa forma, os elementos disponíveis constantes das decisões em consonância com as práticas reconhecidamente úteis podem ser instrumentos hábeis a estimular, desde o início da gestação, as melhores evidências científicas a partir dos casos concretos, seja para possibilitar maior segurança à parturiente, seja para proteger a vida e integridade do feto.

Apesar de pesquisas demonstrarem que a cesariana ofereça maiores riscos para a parturiente e o feto, as decisões judiciais analisadas pelo STJ evidenciaram que os danos que resultaram em sequelas irreversíveis no nascituro foram recorrentes nos casos relacionados ao parto natural, sugerindo que atenção especial deve ser dada na formação médica obstétrica, bem como na compreensão dos aspectos socioculturais envolvendo a indicação e escolha do tipo de parto.

De uma maneira geral, pode-se dizer que, para a questão analisada, o estudo jurisprudencial favorece o estudo qualiquantitativo proposto e se mostra um instrumento valioso para a geração de dados de saúde primários e secundários ligados ao parto natural e cesárea.

Por meio da pesquisa, foram reveladas práticas obstétricas que ainda conflitam com os incentivos a que os órgãos públicos e privados têm recorrido para reduzir o número de intercorrências que gerem danos à mulher e ao nascituro. Tais medidas não poderiam se limitar apenas à escolha do tipo de parto, uma vez que, a bem da verdade, ainda persistem nos sistemas e organizações de saúde a má gestão dos bens públicos, a falta de estrutura, a desorganização e a escassez de recursos básicos, que só retardam a concretização das ações adotadas na tentativa de humanização do parto.

É preciso reformular o modelo de assistência ao parto no Brasil, e não apenas responsabilizar os médicos pelo excesso de cesarianas. Os casos revelam discussões bastante relevantes, que podem ser repensadas como iniciativa para uma mudança gradativa nas relações entre os envolvidos no processo gestacional e puerperal - inclusive os operadores do Direito, que de certa forma aplicam a lei (advogados, Poder Judiciário e demais instituições) ao caso concreto, e os profissionais da saúde obstétrica (médicos, enfermeiros), que atuam diretamente com as dificuldades enfrentadas no exercício da profissão. 
O trabalho revelou resultados que sugerem identificar o predomínio das principais intercorrências do momento puerperal relacionadas ao parto natural e à cesárea, a fim de obter subsídios para as organizações de saúde e, sobretudo, minimizar o ativismo judicial e os riscos decorrentes da má prática médica obstétrica, reduzir custos provenientes das altas indenizações e incentivar a humanização, a qualidade e a excelência na assistência ao parto.

\section{Referências}

ALENCAR JÚNIOR, C. A. Os elevados índices de mortalidade materna no Brasil: razões para sua permanência [Editorial]. Rev Bras Ginecol Obstet., v. 28, n. 7, p. 9-11, 2006. Disponível em: <http://www.scielo.br/pdf/rbgo/v28n7/01.pdf>. Acesso em: 04 dez. 2015.

ALVES-MAZZOTTI, A. J.; GEWANDSZNAJNER, F. O. O método nas ciências naturais e sociais: pesquisa quantitativa e qualitativa. 2. ed. São Paulo: Pioneira, 1998.

ANS publica resolução para estimular parto natural na saúde suplementar Detalhes Notícias ANS, 06 jan. 2015. Disponível em: <http://www.ans.gov.br/aans/noticias-ans/ consumidor/2718-ministerio-da-saude-e-ans-publicam-resolucao-para-estimular-partonormal-na-saude-suplementar\#sthash.da35g6eA>. Acesso em: 30 mai. 2015.

BRASIL. Ministério da Saúde. Secretaria de Políticos de Saúde. Área Técnica de Saúde da Mulher r. Parto, aborto e puerpério: assistência humanizada à mulher. Brasília: Ministério da Saúde, 2001. Disponível em: <http://bvsms.saude.gov.br/bvs/publicacoes/cd04_13.pdf >. Acesso em: 26 out. 2015.

CAI a mortalidade materna no mundo, aponta OMS; redução no Brasil chega a 43\%, 2014. ONUBR. Nações Unidas no Brasil, 07 maio 2014. Disponível em: <http://www.onu.org.br/cai-a-mortalidadematerna-no-mundo-aponta-oms-reducao-no-brasil-chega-a-43/>. Acesso em: 30 nov. 2015.

COACCI, T. A Pesquisa com Acórdãos nas Ciências Sociais: algumas reflexões metodológicas. Rev Ciências Sociais, v. 18, n. 2, p. 86-109, 2013. Disponível em: <http://www.uel.br/revistas/ uel/index.php/mediacoes/article/view/17313>. Acesso em 29 set. 2015. http://dx.doi. org/10.5433/2176-6665.2013v18n2p86.

COX, K. J.; KING, T. L. Preventing primary cesarean births: midwifery care. Clin Obstet Gynecol., v. 58, n. 2, p. 282-293, Jun. 2015. 10.1097/GRF.0000000000000108. Acesso em: 14 jun. 2015.

CRUZ, A. C. S.; CECCON, M. E. J. Prevalência de asfixia perinatal e encefalopatia hipóxicoisquêmica em recém-nascidos de termo considerando dois critérios diagnósticos. Rev Bras Crescimento Desenvolv Hum., v. 20, p. 302-316, 2010. Acesso em: <http://pepsic.bvsalud.org/ pdf/rbcdh/v20n2/13.pdf>. http://dx.doi.org/10.7322/jhgd.19968. Acesso em: 25 mar. 2016.

FEDERAÇÃO BRASILEIRA DAS ASSOCIAÇÕES DE GINECOLOGIA E OBSTETRÍCIA - FEBRASGO. Erro médico no dia a dia da ginecologia e obstetrícia. 2014. [20 set. 2014]. Disponível em: <http://www.febrasgo.org.br/site/?p=2019>. Acesso em: 10 abr. 2015. 
FORMA, K. G. Os acórdãos do STF como documentos de pesquisa e suas características distintivas. FGV Direito SP Research Paper Series, n. 132, 2015. Disponível em: <https://ssrn. com/abstract=2676292>. Acesso em: 20 set. 2015.

GABARDO, E.; MORETTINI, F. T. R. Institucionalismo e pesquisa quantitativa como metodologia de análises de decisões judiciais. Rev. Fac. Direito UFMG, Belo Horizonte 2013; n. 63, p. 151-180. Disponivel em: <https://www.direito.ufmg.br/revista/index.php/revista/ article/download/P.0304-2340.2013v63p151/1433>. Acesso em: abr. 2015>. 10.12818/P.0304$2340.2013 \mathrm{v} 63 \mathrm{p} 151$.

GARFINKEL, A. responsabilidade civil por erro médico segundo a jurisprudência do Tribunal de Justiça do Estado de São Paulo (síntese). Revista Direito GV, v. 3, n. 2, p. 37-58, jul./dez. 2007. Disponível em: <http://bibliotecadigital.fgv.br/ojs/index.php/revdireitogv/article/ download/35181/33986>. Acesso em: 10 out. 2015.

KALLAS FILHO, E. O fato da técnica: excludente da responsabilidade civil do médico. Revista de Direito Sanitário, São Paulo, v. 14, n. 2, p. 137-151, 2013. Disponível em: http:// www.revistas.usp.br/rdisan/article/view/63998>. Acesso em: 10 jul. 2015.

KORNACKA, M. K.; KUFEL, K. Neonatal outcome after cesarean section. Ginekol Pol., v. 83, n. 8, p. 612-617, Aug. 2011. 10.1097/AOG.0b013e3181a66d57.

LANSKY, S. et al. Birth in Brazil survey: neonatal mortality, pregnancy and childbirth quality of care. Cad. Saude Publica, Rio de Janeiro, v. 30, supl. 1, p. 192-207, 2014. Disponível em: <http://www.scielo.br/pdf/csp/v30s1/en_0102-311X-csp-30-s1-0192.pdf>. Acesso em: 14 mar. 2016. http://dx.doi.org/10.1590/0102-311X00133213.

MARTINS-COSTA, S.; MARTINS-COSTA, G.; RAMOS, J.G.L. Parto, encefalopatia neonatal e paralisia cerebral. Femina, v. 37, n., 4, p. 223-227, abr. 2009. Disponível em: <http://www.febrasgo. org.br/site/wp-content/uploads/2013/05/Femina-v37n4-p223.pdf>. Acesso em: 24 fev. 2016.

MAXIMILIANO, C. Hermenêutica e aplicação do direito. 20. ed. Rio de Janeiro: Forense, 2011.

MOTA, A. V. L. Análise do discurso da jurisprudência do STJ nas indenizações por erro médico: impacto no sistema de saúde. 2015. Dissertação (Mestrado) - Universidade de São Paulo. Ribeirão Preto - Faculdade de Medicina de Ribeirão Preto - FMRP/USP, 2015.

MOURA, F. M. J. S. P. et al. Humanization and nursing assistance to normal childbirth. Rev Bras Enferm, Brasília, v. 60, n. 4, p. 452-455, jul./ago. 2007. Disponível em: <http://www.scielo. br/pdf/reben/v60n4/a18.pdf>. Acesso em: 25 out. 2015.

NASCER no Brasil. Pesquisa revela número excessivo de cesarianas. Agência Fiocruz de Notícias, 30 maio 2014. Disponível em: <http://portal.fiocruz.br/pt-br/content/pesquisarevela-numero-excessivo-de-cesarianas-no-pais>. Acesso em: 25 fev. 2016.

NOMURA, R. M. Y.; SEIZO, M.; ZUGAIB, M. O perfil dos médicos denunciados que exercem ginecologia e obstetrícia no Estado de São Paulo. Rev Assoc Med Bras., n. 52, p. 144-147, 2006. Disponível em: $<$ http://www.scielo.br/pdf/ramb/v52n3/a02v52n3.pdf >. Acesso em: 10 ago. 2015. 
OLIVEIRA, D. U. A responsabilidade civil por erro médico. Âmbito Jurídico, v. 11, n. 59, 2008. Disponível em: <http://www.ambito-juridico.com.br/site/?n_link=revista_artigos_ leitura\&artigo_id=3580>. Acesso em: jan. 2015.

$5^{\circ}$ RELATÓRIO Nacional de Acompanhamento do ODM - Objetivos de Desenvolvimento do Milênio e a Construção da Agenda pós-2015. Governo do Brasil, 21 maio 2014. Disponível em: <http://www.brasil.gov.br/governo/2014/05/5o-relatorio-nacional-de-acompanhamentodos-odm-sera-lancado-quarta-21>. Acesso em: 20 ago. 2015.

SEAWRIGHT, J.; GERRING, J. Case selection techniques in case study research: a menu of qualitative and quantitative options. Political Research Quarterl., v. 61, n. 2, p. 294-308, 2008. Disponível em: <http://blogs.bu.edu/jgerring/files/2013/06/CaseSelection.pdf >. Acesso em: 22 out. 2015. 10.1177/1065912907313077.

SPINA, V. P. L.; SÁ, E. C. Perfil das demandas judiciais cíveis por erro médico em Ginecologia e Obstetrícia no Estado de São Paulo. Saúde, Ética \& Justiça, São Paulo, v. 20, n. 1, p. 15-20, 2015. Disponível em:<www.revistas.usp.br/sej/article/download/102820/101109>. Acesso em:20 abr. 2015.

TAKAZONO, P. S.; GOLIN, M. O. Asfixia perinatal: repercussões neurológicas e detecção precoce. Neurociencias, v. 21, n. 1, p. 108-117, 2013. Disponível em: <http://www. revistaneurociencias.com.br/edicoes/2013/RN2101/revisao2101/761 revisao.pdf $>$. Acesso em: fev. 2016. 10.4181/RNC.2013.21.761.10p.

VASCONCELLOS, M. T. L. et al. Desenho da amostra Nascer no Brasil: Pesquisa Nacional sobre Parto e Nascimento. Cad. Saude Publica, v. 30, supl. 1, p. 49-58, 2014. Disponível em: $<$ http://www.scielo.br/pdf/csp/v30s1/0102-311X-csp-30-s1-0049.pdf>. Acesso em: 14 mai. 2015. http://dx.doi.org/10.1590/0102-311X00176013.

WORLD HEALTH ORGANIZATION - WTO. Care in normal birth: a practical guide. Geneva, Switzerland, 1996. Disponível em: <http://whqlibdoc.who.int/hq/1996/WHO_FRH_ MSM_96.24.pdf >. Acesso em: 09 out. 2015.

YIN, R. K. Estudo de caso: planejamento e métodos. Tradução: Christian Matheus Herrera. 5. ed. Porto Alegre: Bookman, 2015.

Thaísa Mara Leal Cintra Rodrigues - Mestre em Ciências pela Faculdade de Medicina de Ribeirão Preto da Universidade de São Paulo; especialista em Direito e Processo do Trabalho e Gestão Jurídica de Empresa pela Universidade Estadual Paulista Júlio de Mesquita Filho. Advogada. Ribeirão Preto/SP, Brasil.

Altacílio Aparecido Nunes - Livre-Docente pela Faculdade de Medicina de Ribeirão Preto da Universidade de São Paulo (FMRP/USP); doutor em Medicina Tropical e Infectologia pela Universidade Federal do Triângulo Mineiro; mestre em Pediatria pela Universidade Federal de Minas Gerais; graduado em Medicina pela Faculdade de Medicina de Itajubá. Professor Associado do Departamento de Medicina Social da FMRP/USP. Médico. Ribeirão Preto/SP, Brasil.E-mail: altacilio@fmrp.usp.br 